
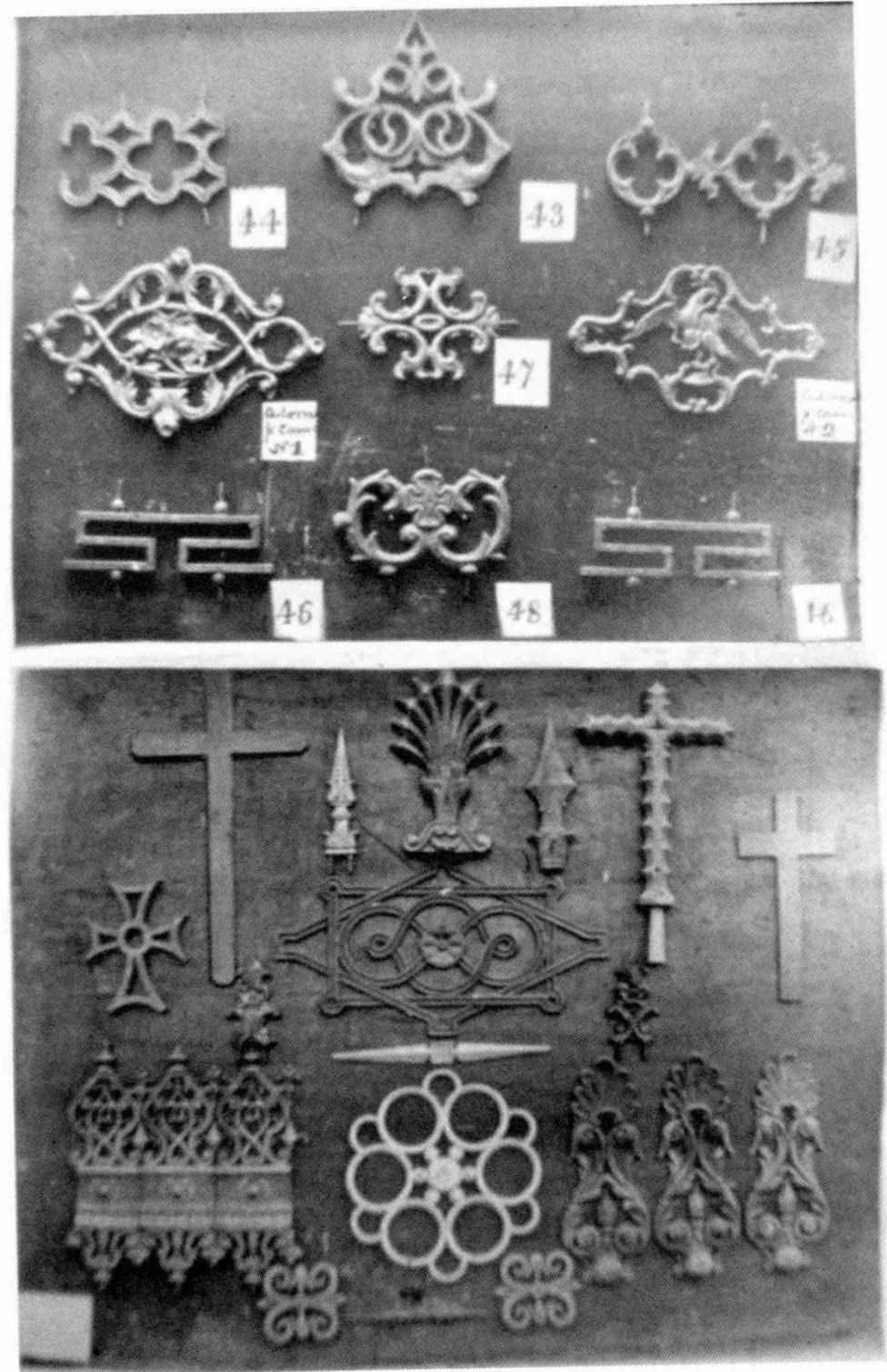


\title{
La divulgación del conocimiento en los almanaques franceses
}

\author{
Lise Andries
}

$\mathrm{L}$ a función principal del almanaque consiste en transmitir información a quienes leen poco. Obra de bajo costo que aparece una vez al año, es a menudo -junto con el devocionario o el misal- el único libro que posee el lector popular. Así lo recuerda el redactor del Almanach historique (Almanaque bistórico) de 1793: "Como pensé que [mis libros] servirían para instruir al pueblo, me pareció que debía hacer los almanaques con el fin de que se propaguen más", y el autor de L'Esprit des almanachs (El espiritu de los almanaques) añade, a propósito de estas obras:

¿Cuántos detalles encantadores no tenemos sobre las ciencias, el comercio, las artes, la historia, la fábula, la geografía, etc.? Son pequeñas miniaturas que nos dan una idea de cada cosa y pueden bastar para muchas personas. Ya que, si para conocer una ciencia fuera necesario recorrer los compendios voluminosos que ésta incluye, ¿quién no se quedaría impedido, detenido, sobre todo cuando no busca en absoluto hacer profesión de ella? ${ }^{1}$

Aquí se afirma la idea de que el almanaque como género editorial se adapta

' Le Camus, Esprit, 1783, p. vIII particularmente a la difusión de la información y que su forma condensada y selectiva facilita particularmente su lectura. Intentaremos subrayar el papel precursor de los almanaques en cuanto a que pueden ser vistos hoy como una primera etapa en la historia de la divulgación científica, en el momento del tránsito entre los siglos XVIII al XIX, época en que las luces y la revolución francesa contribuyeron a modificar el contenido de los almanaques en el sentido de una mayor modernidad y una laicización de los saberes.

Por este motivo, he constituido un muestrario de almanaques aparecidos durante este periodo, provenientes del rico fondo de la Biblioteca Nacional de Francia, privilegiando algunas grandes series: los Messagers boîteux (Mensajeros cojos), los Mathieu Laensberg, los Almanachs des bergers (Almanaques de los pastores), los Dieu soit béni (Alabado sea el Señor) y algunos Étrennes (Año nuevo) parisinos, esencialmente el Petit théâtre de l'univers (Pequeño teatro del universo), el Étrennes intéressantes des quatre parties du monde (Año nuevo interesante de las cuatro partes del mundo), el Désiré des Français, études bistoriques et morales (El deseo de los franceses, estudios históricos y morales) y el Étrennes des quatre parties du monde, bistoriques, utiles et intéressantes (Año nuevo de las cuatro partes del mundo, historico, útil e intere- 
sante). ${ }^{2}$ Varios centros de impresión, sobre todo Troyes, Ruán y París, han sido seleccionados de entre la gran cantidad de aquellos que se especializaron, a finales del siglo XVIII, en la producción popular. Entre los editores, he estudiado a los que representan a los impresores tradicionales de la literatura ambulante y la Biblioteca Azul, como la casa editorial Garnier de Troyes que publica varios almanaques a comienzos del siglo XIX, el Dieu soit Béni, el Almanacb pour l'année... (Almanaque del año...) de Mathieu Laensberg y el Almanach des bergers. ${ }^{3}$ Encontramos asimismo un $\mathrm{Al}$ manach de Liège joumalier (Almanaque diario de Lieja), publicado en Ruán por LecrêneLabbey, otro editor especializado en la venta ambulante. A este corpus hay que añadir los numerosos almanaques aparecidos durante la revolución. ${ }^{4}$ Me pareció interesante seleccionar sobre todo aquellos que se inscribían en una cierta continuidad editorial, en Troyes, Ruán o París.

El estudio de la producción de almanaques en los siglos XVIII y XIX es complejo, en primer lugar, porque un editor puede publicar paralelamente diversos títulos; en segundo lugar, porque un título exito-

${ }^{2}$ Petit, 1786-1789; Étrennes, 1789-1840; Le Désiré, 1815-1848; Étrennes, 1812-1820.

${ }^{3}$ Ediciones del Dien soit Béni para los años 18121844; Almanach par Matbieu Laensberg, años 1812-1815; Almanach des bergers, de 1824-1859. La editora, "ciudadana Garnier", después "mujer Garnier", será reemplazada a su muerte por Baudot, quien vuelve a comprar el fondo Garnier en 1830 y se convertirá en el último editor ambulante de Troyes. Las fechas que se señalan aquí corresponden a las series dispares que posee la Biblioteca Nacional de Francia.

${ }^{4}$ Martin y Walter, Catalogue, 1936, t. v; Andries, "Almanacs", 1989; "Almanache", 1988; "Almanachs", 1.987. so es imitado de manera inmediata por alguna otra casa competidora y, finalmente, porque durante aquel periodo se multiplican los centros de impresión. Así, existen para los Messagers boîteux, los Mathieu Laensberg y los Dieu soit Béni, decenas de casas editoriales y de ciudades diferentes que aportan, cada una, variantes en la composición del almanaque y de sus rúbricas específicas: calendario, predicciones, noticias y anécdotas. Más que estudiar esta producción según su procedencia geográfica, me pareció interesante seleccionar criterios de apariencia material que me han conducido a distinguir tres grandes grupos de almanaques: los Messagers boîteux, que tienen más de un centenar de páginas, cuya presentación y formato en cuarto retoman los del Grand Calendrier des bergers (Gran calendario de los pastores), primer almanaque publicado en Francia a finales del siglo xv (y que deja de aparecer en la segunda mitad del siglo XVII); los Almanachs des bergers, a los que se puede incorporar los Dieu soit Béni, cuyo formato y alternancia de tintas negras y rojas, así como parte del contenido, son semejantes al antiguo Matbieu Laensberg de Lieja, ${ }^{5}$ y finalmente, el conjunto de los "Étrennes parisinos", gruesos folletos de más de 100 páginas, cubiertos de papel coloreado y de formato en $32^{\circ}$, que incluían por lo general un mapa de Francia y un mapamundi. Insisto en esos criterios materiales en primer lugar porque corresponden, a mi modo de ver, a la especificidad de este género editorial que antes que nada prevé la rentabilidad y busca, año

${ }^{5}$ El Dieu soit Béni posee un formato en $12^{\circ}(17 \mathrm{~cm}$ $\times 11 \mathrm{~cm}$; , el Almanach des bergers tiene $10 \mathrm{~cm} \times 6 \mathrm{~cm}$. Imita al Matbieu Laensberg, publicado en Lieja por primera vez en 1634. 
tras año, la fidelidad de los lectores, mediante técnicas de marketing anticipado: conservar siempre el mismo formato y la misma cubierta, inspirarse en modelos más antiguos y prestigiosos, colocarse bajo la enigmática autoridad de "grandes" astrólogos como Mathieu Laensberg. Añádese a ello que los conocimientos difieren entre una categoría y la otra y no ocupan el mismo lugar: son más elementales en el Almanach des bergers, pero más completos y modernos en los Messagers boîteux.

Si estudiamos, por ejemplo, los Almanachs des bergers, constatamos que se renuevan muy poco y constan esencialmente de un calendario que ocupa $90 \%$ de su contenido. Dicho calendario está compuesto en su totalidad por signos icónicos que reemplazan las letras impresas; se enfoca a predecir, para el año venidero y todo revuelto, el clima, los tiempos de las labores del campo, los días en que conviene cuidar su salud en función de las lunaciones y de las conjunciones astrales. Para señalar los días favorables para el corte de cabello, este almanaque imprime un par de tijeras al lado del número arábigo que designa el día en cuestión, o bien, un círculo blanco para indicar el momento en que hay que "tomar la píldora". Otros símbolos sirven para designar los signos del Zodiaco y las lunaciones, los días de trabajo y los días feriados. En lo que respecta a los santos del calendario, éstos se encuentran representados por una imagen a veces muy difícil de descifrar, debido a la pésima calidad de entintado del grabado. Al final de este almanaque se encuentra invariablemente, hasta 1859, la figura de "El astrólogo", personaje ataviado con un traje renacentista que sujeta en la mano un compás, y va acompañado de una divisa algo inquietante:

\section{Je suis le Maître Spectateur \\ Du temps et de son bonheur. ${ }^{6}$}

El contenido de los Dieu soit Béni es muy similar al de los Almanacbs des bergers. Ahí encontramos las fechas y lugares de las ferias y los nombres de los días de la semana; por lo tanto, en estos dos almanaques, la difusión del conocimiento sigue siendo rudimentaria. Consiste en proporcionar reglas de vida inspiradas en el ritmo calendárico, astrológico y lunar, y en indicar hitos temporales al filo del año: ferias, fiestas religiosas, días feriados. Sin lugar a dudas, esta función de los almanaques fue importante para un público al que se enseñaba todos los gestos de la vida cotidiana por la simple consulta del calendario. Ésta se inscribe en un sistema de comprensión del mundo fundado en correspondencias múltiples entre el hombre y el universo, entre el microcosmos y el macrocosmos. Un grabado simboliza estas creencias: es el del "hombre zodiacal", en el que cada parte del cuerpo está ligada a un planeta.

Este grabado figuraba ya en las ediciones del renacimiento del Grand Calendrier et compost des bergers (Gran calendario y miscelánea de los pastores), y continuó apareciendo en los Almanachs des bergers hasta finales del siglo XIX con la siguiente inscripción:

En ces signes ne saignerez

Quand la Lane y fera entrée. felicidad.

${ }^{7}$ En estos signos no sangraréis / Cuando la Luna entre en ellos. 
Los Almanacbs des bergers transmiten, por lo tanto, conocimientos tradicionales relacionados con la astrología y la medicina antigua. Además, se dirigen a un público al que podemos suponer en los lindes del analfabetismo, ya que, en su conjunto, el calendario está constituido por signos icónicos.

Volvemos a encontrar este sistema de signos en el calendario del Messager boîteux con el grabado del hombre zodiacal, que es su continuación lógica, pero en este almanaque el calendario coexiste con una nutrida parte impresa de intención informativa. Se podría considerar que el grupo de los Messagers bô̂teux ocupa una posición intermedia entre los Almanachs des bergers, que transmiten los conocimientos tradicionales, y los Étrennes parisinos claramente orientados hacia la modernidad, principalmente porque no renuncian ni a la astrología en el calendario ni a las predicciones. Lo mismo puede decirse de los Mathieu Laensberg y otros Almanachs de Liège que aparecieron en el siglo XIX. Estas predicciones pueden ser meteorológicas, políticas (anuncian la muerte de algún príncipe, una revolución, la paz) o médicas (tal enfermedad podría atacar al pueblo pobre en tal periodo del año). Por otra parte, conviene subrayar que la parte astrológica de los almanaques siempre tiene una finalidad colectiva y no individual, a diferencia de los horóscopos de la prensa moderna. En el otro extremo habría que colocar los Étrennes parisinos que no recurren nunca a las predicciones, y en los cuales el calendario ocupa sólo una parte ' mínima. En ese aspecto, se inscribe en el filo de la evolución destacada por Le Camus de Mézières, autor de L'Esprit des almanachs, quien declara en 1783 , a propósito de los almanaques de astrología.
"Apenas si lo más bajo del pueblo les concede algún crédito. La mayoría de los almanaques de ahora guardan simplemente el calendario de las fiestas del año." El calendario de los Etrennes parisinos se limita, por su parte, a indicar los días del año, con las fiestas de los santos y las horas de salida y de puesta del sol y de la luna, como lo hacía el Connaissance des temps que publicaba cada año, desde finales del siglo XVII, la Academia de Ciencias. No incluye evidentemente ningún signo astrológico.

Una constatación similar merece el lugar que ocupa la cronología o cuenta del tiempo, rúbrica importante en los almanaques tradicionales que se encuentra al comienzo de la obra, antes del calendario. Hasta finales del siglo XIX, la cronología de las grandes épocas de la humanidad se lee "a contracorriente" del tiempo en los almanaques: así, el Dieu soit Béni y el Almanach des bergers calculan cuántos años han transcurrido desde la creación del mundo, hace poco más de 4000 años, desde el diluvio universal, desde el nacimiento de Jesucristo, desde la introducción del calendario gregoriano, desde el comienzo del reinado de... Señalemos, sin embargo, que l'Almanach royal (Almanaque real), publicación oficial de la monarquía, presenta todo a lo largo del siglo XVIII una cronología idéntica. El arcaísmo de los almanaques populares procede de que un siglo más tarde, la cuenta del tiempo permanece sin cambios, y no puede ser atribuida, entre otras cosas, a una confusión entre tiempos bíblicos y tiempos históricos. Es de notar que el Almanach des bergers añade a su cronología, en 1811, la invención de la brújula, la del cañón, la de los mosquetes, la del telégrafo eléctrico, prueba de que esta rúbrica tradicional soporta cierta adaptación a la modernidad. 
Los Messagers bô̂teux presentan una evolución bastante similar. En el siglo XrX se refieren aún a la creación del mundo, al diluvio universal y a ciertos episodios del Antiguo Testamento. Pero el Messager boîteux de R. Gabriel añade en 1811, la invención de la imprenta, de la pólvora, de la navegación aérea por Montgolfier, la reforma de Lutero, la fundación de Roma y de diversas repúblicas: francesa, bátava, italiana, helvética. ${ }^{8}$ Ciertamente, la influencia de la revolución francesa y de su nuevo calendario se deja ver aquí. En cuanto al Messager boîteux de la girafe parisienne (Mensajero cojo de la jirafa parisina), éste yuxtapone, en una lista al estilo Prévert, la invención de los molinos de agua y de los molinos de viento, y el descubrimiento del Nuevo Mundo. Es preciso constatar, sin embargo, que la fecha de la creación del mundo figura todavía en el Messager boîteux de la girafe parisienne de 1828 y en los Almanachs des bergers publicados en Troyes, hasta 1859. Los Etrennes parisinos se toman más libertades con las cronologías, sea que no incluyan rúbrica de ese tipo, sea que recurran, en su cuenta del tiempo, a criterios históricos como la creación del calendario juliano y la fundación de Roma, en descuido de los acontecimientos bíblicos, contribuyendo así a laicizar la temporalidad de los almanaques. Esta evolución aporta una prueba más de que los Étrennes parisinos se separan de los conocimientos tradicionales y son la categoría de almanaques más abierta a la difusión de la modernidad.

Podríamos evocar, a propósito de estas tres grandes categorías de almanaques, otros criterios de clasificación, lo que vendría a establecer niveles distintos de com-

${ }^{8}$ Véritable, 1811. petencia de lectura y de acceso a la cultura de lo impreso. ${ }^{9}$ Los Almanachs des bergers se situarían en un extremo de la escala, puesto que pueden ser comprendidos por quienes no saben leer, y los Étrennes parisinos en el otro, a causa de sus mapas, su índice y sus esquemas científicos que suponen lectores dotados de cierta habilidad para manipular los textos. Los conocimientos difundidos por los almanaques se encuentran, por consiguiente, estrechamente vinculados a estas modalidades de lectura, según su mayor o menor grado de complejidad. Sin embargo, sería una exageración creer que frente a un género tan proteimorfo y heterogéneo como el almanaque, las fronteras entre los diferentes públicos se marcan de una manera rigurosa.

Durante la revolución, todos estos almanaques continúan apareciendo, adaptándose más o menos a los acontecimientos políticos. Los editores parisinos de almanaques y de Étrennes son los que mejor se adaptan e incluso ganan una buena parte del mercado al responder a las nuevas demandas políticas. Langlois, Caillot y Demoraine, quienes ya publicaban Étrennes bajo el antiguo régimen, se adaptan a la moda del día. Demoraine publica, por ejemplo, en 1793, un Almanach des bergers que rompe completamente con el almanaque tradicional, aunque toma prestado su título y sustituye la astrología por un curso de astronomía que se basa en las enseñanzas del gran astrónomo Lalande. El mismo editor da a conocer en el año III (de la república) un Tableau bistorique des événements révolutionnaires (Cuadro bistórico de los acontecimientos revolucionarios) y un

${ }^{9}$ Véanse los trabajos de Chartier sobre este punto, especialmente Bord, 1998. 


\section{SECUENCIA}

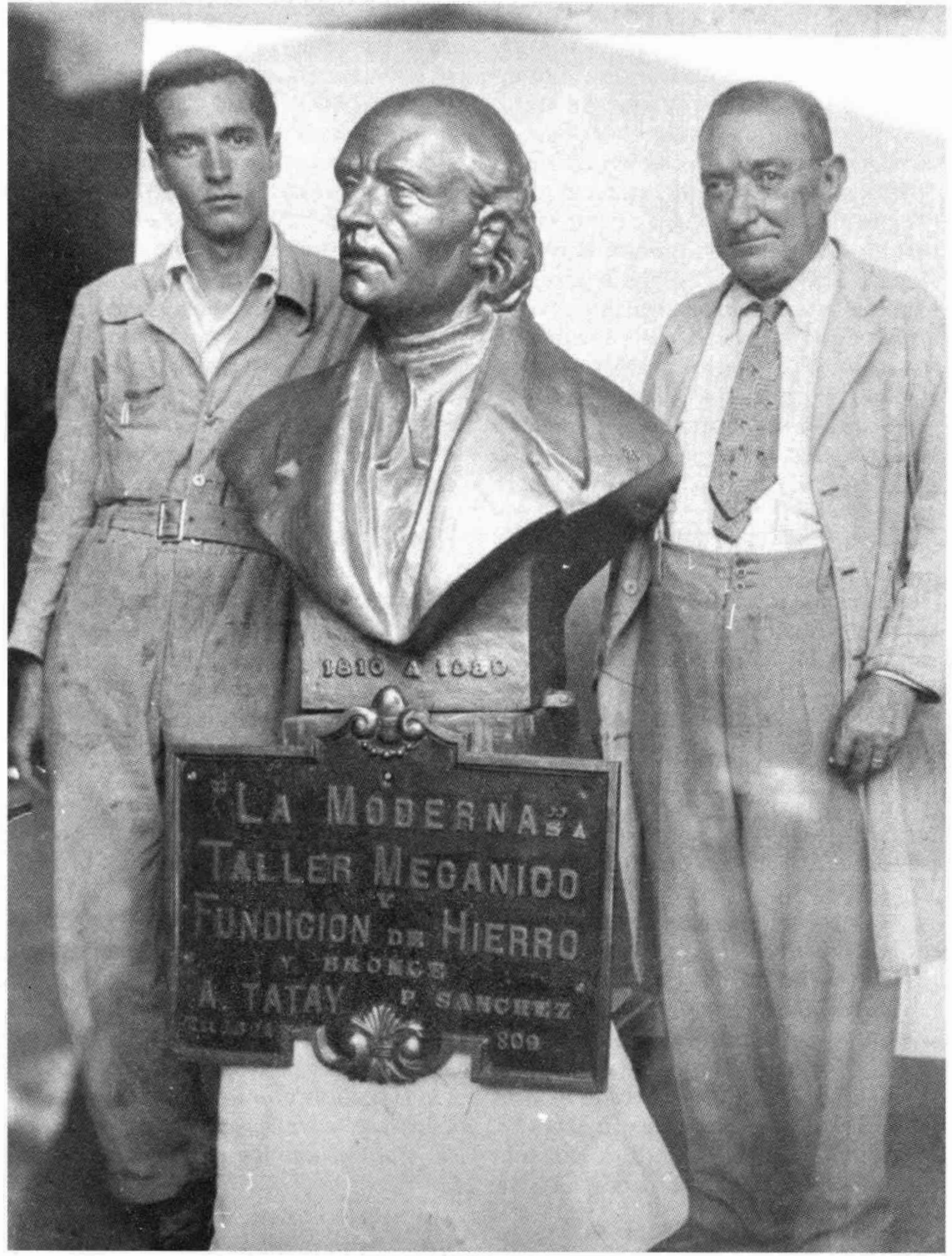


Bonnet rouge ou le retour du siècle d'or (Gorro frigio o el retorno del siglo de oro), compilación de poesías y canciones revolucionarias "dedicada a la mitad más bella de los sans culottes". De hecho, los almanaques se convertirán rápidamente en una apuesta política importante, ya que los revolucionarios comprenden los beneficios que pueden sacar de aquel género editorial ampliamente difundido. Instrumento de propaganda, pero también medio de educación del pueblo y de difusión de los nuevos conocimientos de acuerdo con los principios que vienen en línea recta de los pensadores de las luces, los almanaques se encuentran en el corazón de la aventura revolucionaria.

Condorcet, quien será presidente del Comité de Instrucción Pública en 1791, es el que mejor encarna el gran sueño pedagógico del siglo XviI y de la revolución, con sus cinco Mémoires sur l'instruction publique (Memorias sobre instrucción pública). En su Esquisse d'un tableau des progrès de l'esprit humain (Esbozo de un cuadro de los progresos del espíritu bumano), redactado en 1793-1794, celebra el poder de la ciencia y la cree capaz de producir la perfectibilidad del hombre y de la sociedad. Pronto, después del año III (1794-1795), Laplace, Berthollet, Lagrange, colocándose en la continuidad de estas ideas, organizarán cursos gratuitos en la Escuela Normal y en el Observatorio, pues piensan que la misión de los sabios de la república es expandir el conocimiento para todos. Es en este contexto donde se sitúan las primeras iniciativas de los revolucionarios en torno al Club de los Jacobinos. Mezclando sueño pedagógico y voluntad política, colocan los almanaques y los calendarios en el centro de su dispositivo propagandístico. En 1791, el Club de los
Jacobinos lanza un concurso destinado a coronar al almanaque que sepa inculcar "mejor la historia de nuestra revolución, los cambios en la condición de los franceses, en la idea [que tienen] de sí mismos, de sus derechos, de sus deberes, de sus esperanzas." Este almanaque deberá dirigirse prioritariamente a los habitantes del campo, que entonces representan a la gran mayoría de la población francesa. Este "manual de la gente del campo" constituirá "toda su biblioteca" y deberá también contener, según el tema puesto a concurso, "el calendario de las fases de la luna, de los eclipses, del tiempo propio para la cultura de la tierra, el saber para cada cosa, las precauciones para la salud en ciertas estaciones". Gana el concurso el Almanach du Père Gérard de Collot d'Herbois. Dicho almanaque se puede considerar como la primera obra de divulgación de un saber cívico y político. Pone en escena al Père Gérard, personaje real que fue diputado de la Baja Bretaña en la Asamblea Constituyente y que, según el almanaque, reúne a sus conciudadanos en el pueblo para explicarles la nueva constitución en doce conversaciones. L'Almanach $d u$ Père Gérard tuvo gran éxito editorial y fue traducido inmediatamente en toda Europa. Cuando Collot d'Herbois fue encarcelado tras la caída de Robespierre y abogó en defensa propia, recordó que "L'Almanach du Père Gérard había hecho madurar el amor por la instrucción pública en cada choza del campo". ${ }^{10}$

Simultáneamente, en la prensa republicana, se multiplican los artículos que critican los almanaques tradicionales y las supersticiones que propagan. La Chronique de Paris (La crónica de París) publica por

${ }^{10}$ Collot, Mémoire, año III. 
ejemplo, el 24 de septiembre de 1792 , un artículo anónimo dirigido "A los fabricantes de almanaques", pidiendo que los almanaques se eleven

por fin, este año, al nivel de la révolución. Es importante que nuestros maestros en aquel género se cuiden de no ensuciar los almanaques con tonterías del viejo régimen $\mathrm{y}$ con viejos prejuicios. El pueblo, al que pertenezco, les quedará muy agradecido si suprimen de su obra anual esas naderías meteorológicas y las mentiras que todavía insertan ahí por hábito. Pues tienen más consecuencias de lo que ustedes piensan. El pueblo abre su almanaque todo el año y si no lee en él más que tonterías, corre el riesgo de volverse tonto, cosa que nosotros los patriotas no queremos.

En seguida, el artículo ataca a Le Grand Messager boîteux de Bâle (El gran mensajero cojo de Basilea):

En cuanto al almanaque cojo, se va a enderezar como su país. En cuanto a su instrucción pública, la nación tendrá algún día los medios para mandar hacer sus almanaques con los filósofos, y entonces podrá decirse que el almanaque es el libro que más verdades contiene.

Si, en un primer momento, un almanaque como el de Collot d'Herbois tiene la finalidad de desarrollar la educación cívica de los ciudadanos, se asiste posteriormente, a partir del año II, a una radicalización de los almanaques. Desembarazados de todos los saberes antiguos fundados en una representación mágicoreligiosa del mundo, los nuevos almanaques republicanos están dedicados al culto de la razón. Pero ello no impide que los almanaques tradicionales sigan apareciendo, mediando algunas concesiones al nuevo orden político. El Dieu soit Béni, para el año III, está dedicado al Ser Supremo, pero no deja de ostentar su calendario con los santos y los signos astrológicos, igual que en el pasado. El gran símbolo de esta evolución es la reforma del calendario que implica el establecimiento de una nueva temporalidad, regenerada y racionalizada, ya que el transcurso del año se ve sometido, al igual que los pesos y las medidas, al sistema decimal." ${ }^{11}$ Se trata de considerar, como dice Gilbert Romme en el informe sobre el calendario, que a nombre del Comité de Instrucción Pública, presenta a la Convención en septiembre de 1793, que "el tiempo abre un nuevo libro a la historia".

Durante el año II y el año III (17931795), en una época en que la ley sobre sospechosos señala el fin efectivo de la libertad de prensa, van a aparecer una gran cantidad de nuevos títulos de almanaques $y$ anuarios, que son publicaciones casi oficiales del régimen y que emanan con frecuencia de las administraciones departamentales, como, por ejemplo, el Almanach $d u$ peuple para el año III, redactado por Thiébault, "administrador del departamento de la Meurthe". Al igual que L'ALmanach du Père Gérard, estos almanaques del año II y del año III se dirigen esencialmente a la gente del campo sin cuyo'apoyo, se cree que la revolución no puede triunfar. Como lo señala el Tableau bistorique des événements révolutionnaires (Cuadro bistórico de los acontecimientos revolucionarios), para el año III: "Patriotas del campo, la revolución se hizo principalmente para vosotros". Todos estos almanaques se con-

"Véase también Baczko, "Calendrier", 1984. 
vietten en propagadores de las reformas revolucionarias, es decir, de los nuevos pesos y medidas y del calendario. Este último ha sido concebido, también, para los habitantes del campo. Reemplaza las fiestas religiosas y los santos por días dedicados a las labores del campo y se convierte en un medio de divulgación de los conocimientos y las técnicas agrícolas. Romme, en su informe, evoca este aspecto de su reforma a propósito del cálculo de las fiestas religiosas que acompañaba los calendarios de los almanaques tradicionales.

\begin{abstract}
Nuestros almanaques dejarán de estar cargados de letras dominicales, de números áureos. Hemos buscado lo que podía convenir sobre todo al hombre del campo, cuyo calendario debe ser simple como la naturaleza de la que nunca se separa.
\end{abstract}

En buena lógica, los almanaques republicanos combaten también el contenido astrológico de los almanaques tradicionales y lo reemplazan por páginas de astronomía y de meteorología. Asimismo, algunos intentan difundir consejos de higiene e iniciar a los habitantes del campo en el manejo de nuevos métodos agrarios. El Almanach des bergers de $1793^{12}$ viene acompañado, por ejemplo, de dos mapas celestes e incluye una explicación detallada y precisa de las constelaciones, los eclipses, el Zodiaco y sus signos, latitudes y longitudes, calculadas según el meridiano de París. Cuando aborda la meteorología, su tono se vuelve muy crítico en relación con los almanaques tradicionales:

Ciudadanos, crean a un amigo sincero; hasta el presente, no existe, y quizá nunca existirá,

${ }^{12}$ Almanach, 1793. un método seguro para predecir, con un año de anticipación, la variedad de las temperaturas, y se debe considerar como verdaderos impostores a los autores de los almanaques suizos y alemanes que anuncian el buen tiempo y la lluvia.

Este almanaque dirigido "a los pastores y a los agricultores" justifica la presencia de dos mapas celestes de la manera siguiente:

Éstos les pondrán en condiciones de comparar sus conocimientos de astronomía con los de los alumnos del Observatorio: estos dos mapas son nuevos, habían sido trazados para la instrucción de nuestros antiguos príncipes y de su nobleza, pero ya que la libertad iguala a todos los hombres, les es concedido aprovecharlos.

Constatamos, por lo tanto, que la astronomía no se encuentra nunca muy alejada del discurso político. Hay que subrayar, a este propósito, que los revolucionarios no cuestionan nunca el Zodiaco como división del cielo. Así, Gilbert Romme considera legítimo que el nuevo año revolucionario comience el 21 de septiembre, puesto que es el momento del año en que se ingresa en el signo de Libra, ¡símbolo por excelencia de la igualdad!

En el terreno agrícola, algunos almanaques, como el Almanach du peuple ( $\mathrm{Al}$ manaque del pueblo) para el año III $^{13}$ y el Almanach des campagnes ou l'ami du cultivateur (Almanaque del campo o el amigo del agricultor) ${ }^{1.4}$ enseñan las nuevas técnicas agrarias. Recomiendan la rotación trienal de los cultivos en lugar del barbecho, el

${ }^{13}$ Publicado en Nancy, en casa de Guivard.

14 Almanach, año III. 
uso de las nuevas herramientas agrícolas como el arado de reja, y promueven el cultivo de la papa, del maíz y de los forrajes. Estos almanaques dan también consejos de higiene: no colocar el estiércol cerca de las casas, abrir las ventanas y airear las habitaciones, pavimentar la calle principal del pueblo. Pero es, sobre todo, la obra de Gilbert Romme, el Annuaire du cultivateur (Anuario del agricultor), la que desarrolla mejor y de manera más completa aquellos principios. Galardonado en el 30 de pluvioso, año II (de la república), a raíz de un nuevo concurso destinado, esta vez, a premiar al mejor manual escolar, es enviado por decreto de la convención a todas las escuelas de la república. Este grueso libro, provisto de numerosas láminas explicativas, es sin duda el manual que mejor intenta difundir las nuevas ideas agronómicas en el campo, pero no es un almanaque, aunque posea un calendario y se presente como un "anuario". Empero, su lenguaje y su manejo son demasiado complicados para dirigirse al amplio público de los almanaques. El Annuaire du cultivateur se dirige más bien a aquellos que hoy en día llamaríamos "mediadores culturales", curas de pueblo, maestros de escuela, funcionarios de la república. Al igual que los almanaques, se inscribe en una vasta empresa de educación del pueblo, basada en una laicización y una racionalización de los conocimientos. Pretende generar una verdadera mutación intelectual en el campo. Hay que recordar el papel preponderante de los eruditos en aquellas iniciativas, el del matemático Gilbert Romme o del naturalista Daubenton, quien había publicado algunos años antes una Instruction pour les bergers et pour les propriétaires de troupeaux (Instrucción para los pastores y los propietarios de reba- $\tilde{n} 0 s) .{ }^{15}$ Falta por aclarar si estos almanaques y obras prácticas destinadas al campo cumplieron su finalidad, y si tuvieron una difusión auténticamente popular. En lo que respecta a los almanaques republicanos, podemos dudarlo. Una carta que el comisario del directorio de las Landas dirige a sus superiores en el año VII —en fecha tardía, es cierto-, parece probar que los almanaques tradicionales tienen todavía felices días por delante:

Considero mi deber denunciar ante ustedes los almanaques que se venden con la antigua era y el nombre de todos los santos y las fiestas. No existe medio más adecuado para prolongar el fanatismo; todo el pueblo acude a estos almanaques y desdeña aquellos que sólo mencionan la nueva era. ${ }^{16}$

¿Se deja sentir la influencia de la revolución en los almanaques de comienzos del siglo XIX? Sí, y de manera indudable, incluso si la respuesta debe matizarse, ya que encontramos muy a menudo, en una misma obra, la yuxtaposición de los saberes antiguos y nuevos, sin que sus contradicciones parezcan molestar en lo más mínimo a los redactores. Se ve la reaparición, durante este periodo, de los nombres de los impresores especializados en la literatura ambulante desde el siglo XVIII, los de la "mujer Garnier" en Troyes, Lecrêne-Labbey en Ruán, Deckherr en Montbéliard, Langlois y Démoraine en París para los Étrennes. En este último género, que se desarrolla considerablemente a comienzos del siglo XIX, hacen su apa-

15 Esta obra aparece en París, editada por P. D. Pierres en 1782 y será reeditada durante la revolución.

1.6 Archives Nationales, F17, Departamento de las Landas. 
rición dos nuevos impresores parisinos, Tiger y Janet. En este comienzo de siglo, la mayor parte de los almanaques proclaman el valor de la ciencia y la necesidad de instruirse. El Véritable almanach liégeois (Verdadero almanaque de Lieja) explica por ejemplo que "miseria, servidumbre y desprecio es lo que toca a los ignorantes y sobre todo a aquellos que descuidaron su instrucción durante su juventud". ${ }^{17}$ En estos almanaques, tradición y modernidad coexisten. Las viejas cronologías y cuentas del tiempo se siguen encontrando en los más arcaicos. Los almanaques de Troyes, algunos almanaques de Lieja y los Messagers bot̂teux siguen con la predicción del futuro. Si bien los Almanachs des bergers y los Dieu soit Béni se limitan a prever la meteorología para el año entero, los Almanachs de Liège y los Messagers boîteux se aventuran de una manera general a formular profecías políticas. Pero la tendencia sigue siendo la de reducir el espacio de las predicciones. Asimismo, en la primera mitad del siglo XIX, constatamos que un número cada vez mayor de almanaques se limita a vincular la meteorología con los dichos y la sabiduría popular relativa a la observación de la naturaleza. El Almanach des campagnes (Almanaque del campo) para 1811 , enumera así de manera poética catorce signos anunciadores de lluvia:

cuando las cornejas posadas en la cima de los árboles dejan oír gritos roncos y redoblados, cuando las golondrinas vuelan muy bajo y rozan la superficie del agua, cuando el gallo canta varias veces tras la puesta del sol, o cuando las flores de la pimpinela se cierran. ${ }^{18}$

${ }^{17}$ Véritable, 1827.

${ }^{18}$ Almanach, 1811.
En cuanto al Almanach des campagnes, para 1833, éste precisa que sus previsiones se fundarán únicamente en la observación del barómetro y explica cómo funciona este instrumento y cómo interpretarlo. ${ }^{19}$

Por otra parte, la astronomía se encuentra muy desarrollada en la parte informativa de los almanaques. Bajo su forma vulgarizada, es probablemente la disciplina científica más difundida en los almanaques en aquella época, sobre todo en los Étrennes parisinos, seguida de cerca por la historia y la geografía. Los artículos de astronomía, ya presentes en los Étrennes del siglo XVIII, describen la esfera armilar y sus diferentes círculos, el ecuador, la eclíptica, el meridiano, los trópicos. El Petit théâtre de l'univers de 1786 contiene así un "Tratado claro y preciso de la esfera" en 30 páginas, que es, en realidad, un curso elemental de astronomía por medio de preguntas y respuestas, y explica con claridad el fenómeno de los eclipses, las fases de la luna y las mareas. Hecho novedoso, este almanaque utiliza también esquemas y figuras para apoyar sus demostraciones. Durante el siglo XIX, los almanaques evocan el descubrimiento de nuevos planetas como el de Urano por Herschel en 1781, y el progreso de los conocimientos relacionados con la superficie de la Luna: El Véritable almanach liégeois de Matbieu Laensberg (Verdadero almanaque de Lieja de Mattbieu Laensberg), en una de sus partes titulada "La luna", describe los cráteres y las montañas que se han podido observar sobre ese astro. ${ }^{20}$ Ofrece un sinfín de datos numéricos acerca de la distancia de la tierra a la luna,

19 Almanach, 1833.

${ }^{20}$ Véritable, 1827. 


\section{SECUENCIG}
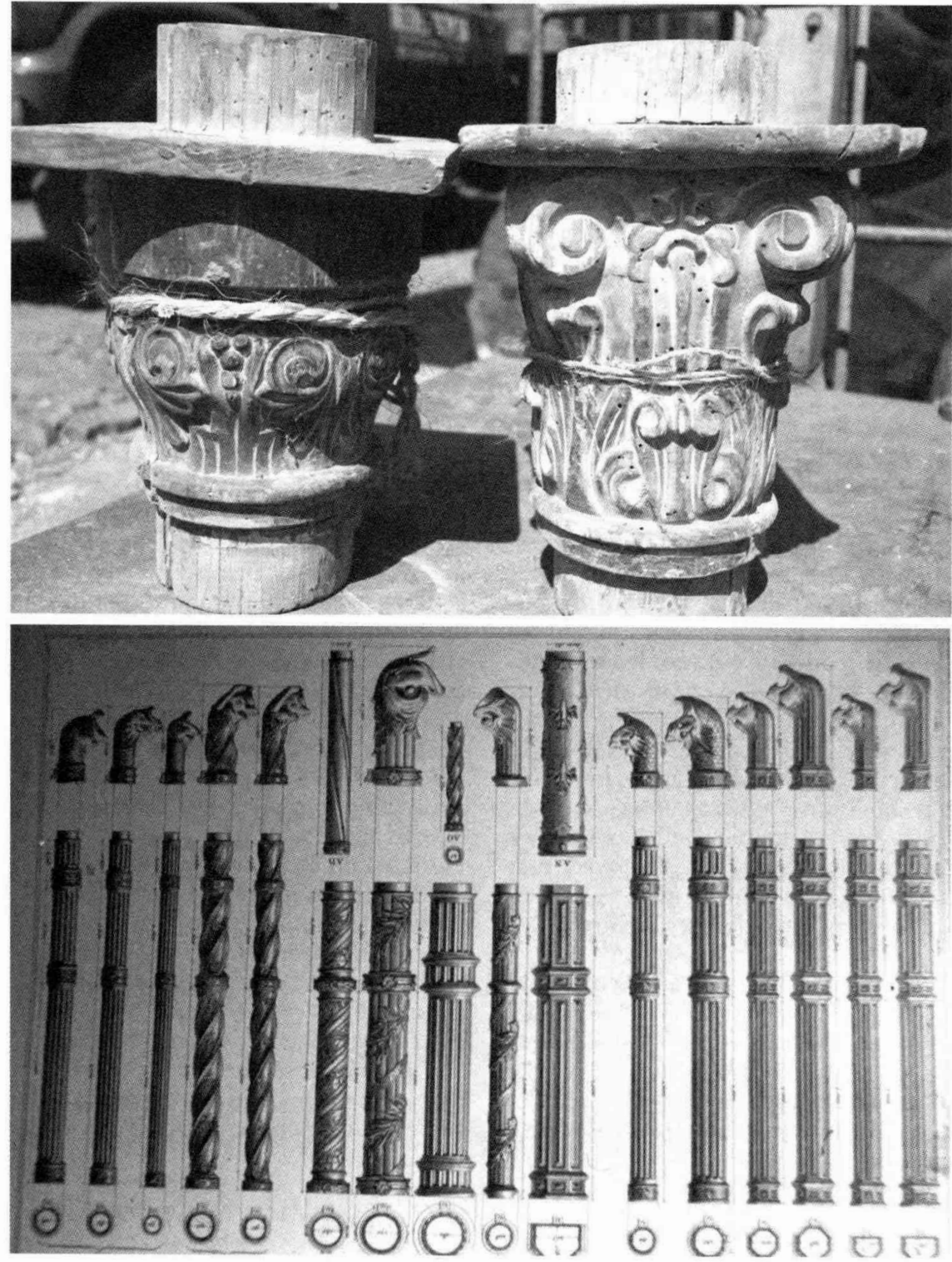
del diámetro del globo terráqueo, etc., medidas que, al ser comprobadas, resultan generalmente exactas. Merece comentario la fascinación por las cifras que encontramos muy a menudo en los almanaques populares del siglo XIX: Las cifras poseen, en efecto, un poder mágico; son dignas de admiración, tanto en lo infinitamente grande, como en lo infinitamente pequeño, $y$ también vienen a ser, para los redactores de almanaques, una prueba de seriedad que legitima el discurso sobre los saberes. Los almanaques, y en particular los Étrennes parisinos, resienten seguramente la influencia de la moda estadística: la Oficina de Estadística se crea en 1800 , el Cuadro de Nacimientos y Mortandad de París, en el año X. Al lado de los datos numéricos relativos a la astronomía, se desarrolla una geografía estadística de la población en la que se puede leer, por ejemplo, el número de centenarios, la población del globo terrestre, etc. Incluso un almanaque poco abierto a las novedades como el Dieu soit Béni, publica en 1819 un cuadro de la Población del globo terráqueo, que indica, para Europa, 160000000 de habitantes, 580000000 en Asia y una cifra de 20000000 de habitantes para las "tierras polares", cifra que deja estupefacto al lector actual.

$\mathrm{La}$ influencia de los grandes naturalistas del siglo XVIII también se deja sentir, y Buffon es probablemente el autor que se menciona más a menudo, aunque sin indicar sus obras de manera precisa. La jirafa que el pachá de Egipto ofreció a Carlos X en 1827 excitó a tal grado las imaginaciones, que dos Messagers boîteux se apropian de ella en su título, el Messager boîteux de la girafe parisienne y el Véritable messager boitteux à la girafe (Verdadero mensajero cojo de la jirafa) ${ }^{21}$ Esta jirafa, que atrajo a turbamultas de curiosos todo a lo largo de su recorrido de Marsella a París, se hace merecedora de unas descripciones físicas minuciosas en estos almanaques: "la jirafa tiene cierto parecido con el camello, por la forma de su cabeza y la longitud de su cuello", e incluso propicia accesos de orgullo nacional: "La llegada de este cuadrúpedo a Francia señalará una época en los anales de la historia natural. Vendrá a ser un motivo suplementario para atraer a los extranjeros a la capital." ${ }^{22}$ Los almanaques dedican también un amplio espacio a los descubrimientos y las invenciones: los primeros viajes en globo aerostático, con las distancias recorridas y los nombres de los intrépidos aeronautas, abren el Petit théâtre de l'univers de 1786. En el Véritable messager boitteux à la giraffe de 1829, un artículo se consagra al batiscafo, "nuevo sistema de navegación submarina, con barcos de fondos abiertos a voluntad", inventado dos años antes. Se ve que aquí el almanaque sigue muy de cerca la actualidad. El mismo almanaque consagra otro artículo a una lograda experiencia de transfusión de sangre. Pero son sobre todo los prodigios y los cataclismos lo que interesa a los autores de almanaques. De este modo, siguen una larga tradición que se remonta a los "pliegos sueltos" del renacimiento. Ciertamente, las ciencias y su progreso encontrarán de ahora en adelante su lugar en los almanaques,

${ }^{21}$ El primero fue impreso en Metz en 1828 por Verronnais y vendido en París por Caillot, por la Viuda Demoraine y Boucquin , y por Janet. El segundo fue publicado por Deckherr en Montbéliard de 1829 a 1854.

${ }^{22}$ Messager, 1828. 
sobre todo en los Messagers boîteux y en los Étrennes parisinos, pero si la astronomía y la historia natural adquieren tanta importancia, las más de las veces es para dar validez científica a la atracción tradicional de esta literatura por las maravillas de la naturaleza, los animales extraordinarios, los "cameleopardos", la "mandrágora que duerme" y los "guisantes que han germinado en una oreja", mencionados en el Trésor des almanachs (Tesoro de los almanaques) de 1793 , junto con prodigios celestes, volcanes, inundaciones, tormentas, "nieves rojas", "lluvias de aerolitos". Las erupciones volcánicas son merecedoras de un lugar preferencial. De este modo, el Almanach de Liège, journalier, que relata los acontecimientos de septiembre de 1810 , asocia curiosamente una "gran erupción del Vesubio" que tuvo lugar el 12, y el "El establecimiento de una Compañía de seguros contra incendios en $\mathrm{Pa}$ rís", el 18 de septiembre. ${ }^{23}$

La historia, la geografía, los viajes constituyen igualmente secciones en pleno desarrollo en los almanaques del siglo XIX, sobre todo cuando se trata de describir regiones exóticas. Este interés por los países lejanos es muy antiguo en los almanaques, pero en el siglo XIX se acompaña de mayor rigor y precisión. Por ejemplo, la gran originalidad de los Étrennes parisinos, en relación con otros almanaques, es la de incluir casi siempre mapas de Francia, y de Europa, así como un mapamundi con la rosa de los vientos. Incluso los Étrennes mignonnes parisiennes (Lindo año nuevo parisino) de 1814 publica, al reverso del mapamundi, el cuadro de la población de los departamentos del imperio francés con el nombre de sus ca-

${ }^{23}$ Almanach, 1812. beceras de distrito. Las descripciones de países lejanos, de sus costumbres, de su fauna y de su flora, proceden de autores y de viajeros cuyos nombres están indicados generalmente en los almanaques. Se asiste así, en los almanaques del siglo XIX, a una apertura formidable sobre el mundo, acompañada, por desgracia, de un eurocentrismo triunfante. El mapamundi de Etrennes intéressantes des quatre parties $d u$ monde de 1789 indica el trazo del viaje de Cook para descubrir las tierras australes; este almanaque añade, hacia 1800 , una sección titulada "Historia de las naciones" que cada año dedica sus artículos a diferentes países, de preferencia lejanos y exóticos, como Brasil, las islas Marianas, Nueva Granada. Se puede leer en un ejemplar de este almanaque que data del año XIII (1804-1805) que Brasil

está limitado al norte por el mar, al oeste por la región de las Amazonas, al sur por el Paraguay. Es el principal recurso de los portugueses. Sus aguas son excelentes, el aire bueno aunque algo caliente, la tierra fértil y excelente [...] Se encuentran ahí monos, pericos y gran cantidad de otros animales. También se ve un pájaro llamado colibrí, no más grueso que una mosca, que canta como ruiseñor.

Los Etrennes intéressantes des quatre parties du monde recuerdan que la población de Brasil fue antaño "salvaje y caníbal" y que "las costumbres de este pueblo han cambiado mucho de aspecto: los jesuitas, por medio de cuidados y sufrimientos inconcebibles, han logrado civilizarlos". ${ }^{24}$

En general, los artículos de geografía de los almanaques impresionan por su eurocentrismo. Tal como lo señala Anne-

${ }^{24}$ Etrennes, año xill. 
Marie Paris, "el almanaque preparó psicológicamente a sus lectores para el colonialismo del siglo XIX, del mismo modo que justificó las intervenciones militares francesas entre 1792 y $181{ }^{\prime \prime} .{ }^{25}$ Se puede leer, por ejemplo, en los Etrennes historiques et universelles (Año nuevo bistórico y universal) de 1828, que dividen al globo terráqueo en cuatro grandes continentes, que en Asia "las costumbres son en general blandas, afeminadas y amigas del ocio", que los africanos tienen "costumbres, feroces, cobardes y pérfidas, según algunos viajeros, y según otros, cercanas al candor y a la simplicidad de los primeros tiempos". El almanaque no habla de América, pero a propósito de los habitantes de Europa, dice que estos "pueblos son dulces, honestos y valientes". Para los almanaques, la tierra es lo más interesante que existe en el universo; en la tierra, Europa se lleva todos los sufragios y, en Europa, Francia está por encima de cualquier otro país. A ese nacionalismo sin freno corresponde un antropocentrismo asociado a un racismo que ni por un instante se cuestiona a sí mismo. Si, según los Étrennes historiques et universelles de 1828, el hombre es "de entre todas las producciones animales, la más maravillosa", 26 el hombre blanco triunfa de manera incontestable sobre el resto de la humanidad. Esta jerarquización de los países y las razas es una tendencia que se afirma cada vez más en los almanaques franceses de la primera mitad del siglo XIX, al tiempo que se acentúa el sentimiento nacionalista.

En los Étrennes parisinos, donde generalmente ocupa una sección completa, la historia comienza con Pharamond y Clo-

${ }^{25}$ Véase Paris, "Diffusion", 1980, p. 217.

${ }^{26}$ Étrennes, 1828. dion "el Cabelludo", primeros reyes de Francia que pertenecen al pasado mítico de la historia de este país, mismos que se encuentran en los libros de historia de la Biblioteca Azul desde el siglo XVII. ${ }^{27}$ Ésta se prolonga con la evocación de las diversas dinastías que les han sucedido hasta llegar a la actualidad. Pero los Étrennes intéressantes des quatre parties du monde se remontan mucho más lejos en el tiempo, ya que dividen la historia del mundo en siete épocas, que van desde la creación, pasando por el diluvio, hasta nuestra era, ${ }^{28}$ y los Étrennes bistoriques et universelles de 1828 , en los que 30 páginas están dedicadas a la historia, recorren la historia de la humanidad desde los tiempos bíblicos, el génesis y el pecado original, el diluvio (ocurrido en el año 1307 antes de nuestra era) y los reinos de Abraham y Moisés, hasta el rapto de Helena, las conquistas de Alejandro, Pharamond, Carlomagno, el buen rey Enrique IV y la revolución francesa. Se ve que esta evocación, en la cual los mitos cristianos y antiguos se mezclan con la historia de Francia, no se encuentra tan alejada de las viejas cronologías de los almanaques tradicionales. Cuando llegan a abordar la actualidad, las páginas de historia de los almanaques exponen claramente sus opiniones políticas. El Désiré des Français de 1815 consagra varias páginas a la entrada de Luis XVIII a París y elogia a los Borbones, mientras que los Étrennes mignonnes aparecidos, es verdad, un año antes, celebran la munificencia de Napoleón. Los almanaques de las primeras décadas del siglo siguen, a menudo de manera conformista, la ideología de los regímenes establecidos, motivo por el

\footnotetext{
${ }^{27}$ Véase Histoire, 1608.

28 Étrennes, 1789.
} 
cual puede uno preguntarse en qué medida pueden haber sido utilizados como instrumentos de propaganda.

Es en el ámbito agrícola donde la herencia de la revolución y de las corrientes fisiócratas de las luces se deja percibir más claramente. También es posible encontrar en los almanaques las grandes líneas de la política gubernamental de modernización del campo que desembocará en la creación del Ministerio de Agricultura bajo la monarquía de Julio. El Messager boîteux de la girafe parisienne, continuador en ese aspecto de los almanaques revolucionarios, critica el recurso tradicional al barbecho y aconseja recurrir a la rotación trienal de los cultivos. También recomienda alternar el cultivo de los cereales y de los forrajes con el fin de no empobrecer la tierra. Le Véritable almanach liégois de Matbieu Laensberg (El verdadero almanaque de Lieja de Matbieu Laensberg), publicado en París en 1828, propone a sus lectores predicciones sacadas de Nostradamus, pero a renglón seguido dedica a la agricultura una parte importante de su "Relación". Describe la visita a una granja y a un establo modelo, elogia los méritos de distintas clases de arados, habla del Instituto Agronómico de Grignon, del cual "el señor delfín ${ }^{29}$ es, después del rey, el principal accionista" y concluye ese capítulo saludando "el impulso que el gobierno desea dar al mejoramiento de la agricultura". En cuanto al Almanach des campagnes de $1811,{ }^{30}$ éste contiene un "Calendario agronómico, o indicación de todas las labores del campo, y de varios

29 Título que se daba al príncipe heredero del trono en Francia.

${ }^{30}$ Publicado en Dijon, Bureau du Journal de la Côte-d'Or. procedimientos económicos y lucrativos", y explica, en particular, cuáles son las diferentes categorías de tierras y cómo mejorarlas. Este almanaque concluye con algunas recetas de medicina doméstica a base de agua, huevos batidos y aceite de oliva para curar especialmente los dolores de muelas y los sabañones. Subrayemos aquí que la medicina, como otros ámbitos, presente en los almanaques del siglo XIX, mezcla tradición y modernidad, herbolaria, automedicación doméstica y progresos de higiene.

Esta curiosa escritura fragmentada es propia, en efecto, de los almanaques con su imbricación de viejos y nuevos saberes en una especie de mosaico. Se comprobará, sin embargo, que en siglo XIX el aval científico se ha vuelto necesario, incluso cuando se trata de evocar los prodigios naturales y las catástrofes que constituyen el material de base del negocio de los almanaques desde su origen. Este fenómeno es nuevo y merece ser subrayado. Se está formando toda una retórica que procura citar a los científicos reconocidos, como Buffon, el astrónomo Lalande y Newton, en lugar de los antiguos astrólogos. A veces también ocurre que las referencias científicas legitiman discursos que carecen de todo rigor. Así el Messager boîteux de 1811 escribe en su "Relación":

El 17 de enero cayó nieve roja sobre las montañas por el rumbo de Plaisance. En ciertas partes, sólo tenía un color melocotón, pero en otras, era de un rojo oscuro [...] Estos hechos fueron asentados en actas, y Maese Guidoti, químico de Parma, se ocupó de analizar esta sustancia y promete resultados interesantes. ${ }^{31}$

${ }^{31}$ Messager, 1811. 
Asimismo, los almanaques comienzan a citar sus fuentes, artículos de periódicos, obras científicas, reportes de experimentos. Aquí el efecto de verdad y sobre todo el proceso de autentificación de las noticias, cobran su plena importancia, y sería erróneo ver en ello solamente un artificio retórico: todos esos fenómenos convergen para mostrar que los lectores se han vuelto más exigentes y que los redactores están al acecho de las noticias de actualidad. De ahí en adelante, el tiempo del almanaque, más lento que el de los otros diarios debido a su periodicidad anual, se va a acercar al presente y voltea hacia el futuro, un futuro que no necesita ya de los pronósticos. Sin embargo, imaginar estos almanaques como más serios de lo que son verdaderamente, sería deformar la realidad. Instruir y divertir, tal es su finalidad. Aquí hemos privilegiado su contenido científico, pero no debemos olvidar que coexiste, a veces en la misma página, con chistes, anécdotas y predicciones que no siempre son de tomarse en serio. Además, la propia ciencia puede convertirse en tema de bromas. ¿Qué pensar, por ejemplo, de este almanaque, amante de las estadísticas, que anuncia que hay 140000 cabellos en una cabeza ordinaria, 3500000 letras en un volumen de la Enciclopedia, que la velocidad de un hombre al pasearse es de cuatro pies por segundo y la de un reno al jalar un trineo en Laponia es de 26 pies por segundo? ${ }^{32}$ Consideremos que si bien le hemos dado al conocimiento científico el sentido que podían prestarle los hombres de las luces -agronomía, astronomía, historia natural, historia y geografía - también están presentes en los almanaques otras formas de

$$
{ }^{32} \text { Etrennes, } 1813 .
$$

conocimiento más modestas, pero que no deben ser descuidadas: la indicación de las fechas y los lugares de las ferias, de las salidas de las diligencias y de las tarifas del correo. Todas estas informaciones responden a la necesidad fundamental de ubicarse en el curso del año, necesidad propia de una Francia rural en la cual el sonido del Ángelus, las fiestas religiosas y los días consagrados a los santos, las fases de la luna, las sombras del sol y los grandes ciclos agrarios eran muchas veces el único medio, fuera de los almanaques, para conocer el tiempo que pasa.

\section{BibliografíA}

-Almanach des bergers, Bouqueton y Démoraine, París, 1793.

- Almanach des campagnes ou l'ami du cultivateur, Meurant, París, año ㅍ. - Almanach des campagnes pour 1811, Bureau du Journal de la Côte-d'Or, Dijon, 1811.

- Almanach des campagnes, Bureau du Journal de la Côte-d'Or, Dijon, 1811.

-Almanach des campagnes, Rambervilliers, Méjeat, 1833.

-Almanach de Liège journalier, Lecrêne-Labbey, Ruán, 1812.

-Almanach du peuple, Guivard, Nancy, año III. - Almanacb par Matbieu Laensberg, 1812-1815. -Andries, L., "Almanachs et littérature révolutionnaire" en Robespierre $\mathcal{E}$ Co., CLUEB, Bolonia, 1987.

—_ "Die Almanache des Jahres II" en R. Koselleck y R. Reichardt (eds.), Die Französisches Revolution als Bruch des gesellschaftlichen Bewusstseins, R. Oldenbourg, Munich, 1988.

, "Almanacs: revolutionnizing a traditional genre" en R. Darnton y D. Roche (eds.), Revolution in print, University of California Press, Berkeley, 1989. 
-Baczko, B., "Le calendrier républicain" en Les lieux de mémoire, t. 1, La République, Gallimard, París, 1984.

-Chartier, R., Au bord de la falaise: l'bistoire entre certitudes et inquiétude, Albin Michel, París, 1998. año III.

-Collot D' Herbois, J. M., Mémoire Justicatif,

-Dieu Soit Beni, 1812-1844.

-Étronnes des quatre parties du monde, bistoriques et intéressantes, Tiger, París, 1812-1820.

-Étrennes des quatre parties du monde, Tiger, París, 1813.

-Etrennes intéressantes des quatre parties du monde, Langlois, París, 1789.

-Etrenner intéressantes des quatre parties du monde, Langlois y después Janet, París, 1789-1840.

-Etrennes intéressantes des quatre parties du monde, Langlois, París, año XIII.

-Étrennes bistoriques et universelles, París, Caillot, 1828.

-Histoire de France avec les figures des roys, depuis Pharamond jusques au roy Henry III, à présent regnant, Jean Oudot, Troyes, 1608.

-Le Camus de Mézières, L'Esprit des almanachs, Veuve Duchesne, París, 1783.
-Le Désiré des Français, études historiques et morales, París, Janet, 1815-1848.

-Martin, A. y A. Walter, Catalogue de l'bistoire de la Révolution française, Editions des $\mathrm{Bi}-$ bliothèques Nationales, Patís, 1936, t. v.

-Messager boîteux, Pierre Gabriel, Vic, 1811.

-Messager boîteux de la girafe parisienne, Verronnais, Metz, 1828.

-Paris, A. M., "La diffusion de l'information scientifique dans les almanachs populaires pendant la Révolution et l'Empire" en La diffusion de l'information et du savoir de 1610 à nos jours, Actes du $105^{\mathrm{e}}$ Congrès des Sociétés savantes, Caen, 1980.

-Petit théâtre de l'univers, Langlois, París, 1786-1789.

-Pierres, P. D. (ed.), Instruction pour les bergers et pour les propiétaires de troupeaux, París, 1782.

-Véritable almanach liégeois, París, Demoraine, 1827.

-Véritable almanach liégeois de Matbieu Laensberg, Demoraine y Boucquin, París, 1827.

-Véritable messager boîteux, pour l'an de grâce 1811, R. Gabriel, Vic, 1811. 